\title{
The impact of time and repeated exposure on famous person knowledge in amnestic Mild cognitive impairment and Alzheimer's disease
}

Sophie Benoit1, Isabelle Rouleau1,2, Roxane Langlois1, Valérie Dostie3, Marie-Jeanne Kergoat4,5, Sven Joubert 3,6

1 Département de psychologie, Université du Québec à Montréal, Canada.

${ }_{2}$ Centre de recherche du Centre hospitalier de l’Université de Montréal, Canada.

3 Département de psychologie, Université de Montréal, Canada.

${ }_{4}$ Département de médecine, Université de Montréal, Canada.

5 Clinique de cognition, Institut universitaire de gériatrie de Montréal, Canada.

6 Centre de recherche de l'Institut universitaire de gériatrie de Montréal, Canada.

\begin{abstract}
Author note
This work was supported by a grant from the Alzheimer Society of Canada to SJ and IR. SJ is supported by a Chercheur-boursier senior award from the Fonds de recherche du Québec en santé (FRQ-S). SB was supported by scholarships from the Canadian Institutes of Health Research, the Fonds de recherche du Québec en santé and the Natural Sciences and Engineering Research Council of Canada. We thank Mélanie Vendette, Karine Thorne, Dr. Juan Manuel Villalpando, Dr. Josée Filion, Dr. Martine Lafleur, Dr. Hélène Masson, Dr. Fadi Massoud and Dr. Yan Deschaintre for their help in recruiting patients. We are also very thankful to all the participants for their time and effort in this study.
\end{abstract}


Correspondence concerning this article should be addressed to Sven Joubert, Centre de recherche de l'Institut universitaire de gériatrie de Montréal, 4565 Chemin Queen-Mary, Montréal, Québec, H3W 1W5, Canada. Telephone: 1-514-340-3540 \#3551. Fax: 1-514-3403548. E-mail: sven.joubert@umontreal.ca 


\begin{abstract}
Objective: Famous people knowledge has been shown to be impaired early in Alzheimer's disease (AD) and amnestic mild cognitive impairment (aMCI). However, the question of whether recently acquired knowledge is more impaired than remotely acquired knowledge remains a matter of debate. The aim of this study was to investigate the patterns of semantic memory impairment in aMCI and AD by investigating two factors that may influence the retrieval of such knowledge, namely remoteness and frequency of repetition of information over time. Method: Three groups (19 controls, 20 aMCI and 20 AD patients) were compared on a test assessing general and specific biographical knowledge about famous people, where the period of acquired fame (remote vs recent) and the type of fame (enduring vs transient) were controlled for. Results: Global performance of aMCI and AD patients was significantly poorer than that of controls. However, different patterns of recall were observed as a function of time and type of fame. A temporal gradient was found in both patient groups for enduring names but not for transient ones, whereby knowledge about remote enduring famous persons was better recalled. Patients were more impaired at questions assessing specific biographical knowledge (unique to an individual) than more general knowledge. Conclusions: Tests of famous people knowledge offer a unique opportunity to investigate semantic deficits in aMCI and AD, because they make it possible to estimate the time at which memories were acquired, as well as the type of fame. Results are discussed in light of memory consolidation models.
\end{abstract}

Keywords: Mild cognitive impairment, Alzheimer's disease, Semantic memory, Famous names 


\section{Public significance statement}

This study assessed semantic memory in Alzheimer's disease (AD) and amnestic mild cognitive impairment (aMCI), using a test of famous person knowledge. Results revealed that the aMCI group showed significant semantic deficits, although less severe than in the AD group, and that performance was influenced by several specific factors, like the type of fame (enduring vs. transient) and the period (remote vs. recent). 
Semantic memory encompasses declarative knowledge about the world, such as knowledge about objects, people, places, concepts, facts and language, acquired over a lifetime and shared across individuals of a given cultural group (Tulving, 1972). Semantic deficits have been widely documented in Alzheimer's disease (AD) and occur early in the disease process (Amieva et al., 2008; Wilson, Leurgans, Boyle, \& Bennett, 2011).

In the past decade, an increasing number of studies have described semantic deficits in patients with amnestic Mild Cognitive impairment (aMCI), a condition typically considered to be a prodromal phase of AD (Adlam, Bozeat, Arnold, Watson, \& Hodges, 2006; Hodges, Erzinclioglu, \& Patterson, 2006). Knowledge about unique entities appears to be particularly vulnerable to semantic breakdown in aMCI, as opposed to more generic knowledge. Thus, several studies reported greater impairment for unique entities with distinctive features, such as famous people, famous monuments or famous public events, than for non-unique and more generic concepts such as man-made objects and animals (Ahmed, Arnold, Thompson, Graham, \& Hodges, 2008; Borg, Thomas-Anterion, Bogey, Davier, \& Laurent, 2010; Clague, Graham, Thompson, \& Hodges, 2011; Joubert et al., 2010; Joubert et al., 2008; Thompson, Graham, Patterson, Sahakian, \& Hodges, 2002). Some studies have even suggested that impaired semantic processing of famous persons may contribute to identifying patients who present with an increased risk of developing AD in the following years. More specifically, longitudinal studies have shown that aMCI patients who later on converted to AD were initially more impaired at naming famous faces relative to non-converters (Estevez-Gonzalez et al., 2004; Thompson, et al., 2002; Vogel, Gade, Stokholm, \& Waldemar, 2005).

Still, very little is known about the specific factors that modulate this semantic breakdown for famous persons among aMCI and AD patients. For instance, the time when 
knowledge was initially encoded in semantic memory has been rarely considered. However, the moment at which semantic knowledge was acquired is important, since remote information has been shown to be better recalled than more recent information. Indeed, some studies have documented better performance of aMCI and $\mathrm{AD}$ patients with older material, using various types of stimuli, like famous faces (Delazer, Semenza, Reiner, Hofer, \& Benke, 2003; Greene \& Hodges, 1996; Hodges, Salmon, \& Butters, 1993), famous names (Seidenberg et al., 2009) and public events (Bizzozero, Lucchelli, Saetti, \& Spinnler, 2009).

Yet, a temporal gradient has not been systematically found and other studies have shown similar patterns of impairment across all periods studied. For example, no significant temporal gradient was found by Thompson et al. (2002) when the recognition, naming and identification abilities of early $\mathrm{AD}$ patients were measured with pictures and names of famous persons from two different periods (1950s and recent). Similarly, Barbeau et al. (2012) administered a famous face naming task to aMCI patients and found no trend for a temporal gradient on any of the six periods studied. Using famous public events, Leyhe et al. (2010) investigated the patterns of retrograde memory of early aMCI and $\mathrm{AD}$ patients and found that performance was uniformly affected across five time segments and no significant temporal gradient was detected.

Thus, the existence of a temporal gradient among aMCI and AD is still a matter of debate. Such discrepancies in the literature may arise in part from the type of stimuli employed to evaluate the integrity of semantic memory. Although some studies have taken into account the time interval since public figures first achieved fame when assessing famous person knowledge, very few have considered the type of fame itself. In fact, the amount of exposure to famous people in the media may be critical in better understanding the nature of the breakdown of famous person knowledge in aMCI and AD. Indeed, information about famous public figures 
who are still famous today have been frequently repeated in the media throughout the years (enduring fame). Because of this continued exposure, knowledge about these persons may be less vulnerable to semantic decline, as opposed to knowledge about famous persons who are no longer frequently exposed in the public domain (transient fame).

Therefore, the aim of the current study was to further investigate the patterns of retrograde semantic memory for famous persons while considering both the period of fame (remote vs. recent) and the type of fame (brief vs. long-lasting public exposure). Indeed, taking into account such factors should lead to a better understanding of the nature of the retrograde memory impairment in aMCI and AD. In a recent study, Langlois et al. (2016) controlled for the enduring vs. transient nature of public events, and a complex pattern of impairment emerged. First, memory for transient public events was more impaired in aMCI and in AD than in controls, regardless of the period, while memory for enduring public events was only impaired in AD. No specific pattern of temporal gradient emerged. The present work investigated the same variables, but through the assessment of famous person knowledge. Indeed, famous persons and famous public events are both unique and idiosyncratic, and therefore are both semantic domains affected early in aMCI and in AD (Leyhe et al., 2010; Joubert et al., 2010), but they also represent different conceptual categories of knowledge. Therefore, it is difficult to predict if they will be differently affected in aMCI and AD.

In order to address this question, the performance of three groups of participants (healthy older controls, aMCI and AD patients) was examined on a detailed test assessing semantic knowledge about famous persons, that controlled for: 1) the type of fame (enduring vs. transient) and 2) the time (remote vs. recent). For each public figure, a general question regarding their occupation was asked, followed by a specific question tapping distinct biographical information. 
It was expected that the aMCI group would perform worse than the control group, but better than the AD group. Both aMCI and AD groups were also expected to show less deficits for enduring than for transient famous persons, reflecting greater cumulative exposure over time to the former. In addition, based on findings from recent studies (Barbeau, et al., 2012; Langlois, et al., 2016; Leyhe, et al., 2010; Thompson, et al., 2002), we did not expect to find any specific temporal gradient, regardless of the nature of fame. Finally, we wanted to explore how performance was influenced when semantic knowledge had to be processed on a general or a specific level. Considering the fact that distinctive and unique features appear to be vulnerable in aMCI and $\mathrm{AD}$, we expected greater impairment among both patients groups with material tapping specific biographical information (unique to an individual), as opposed to material tapping more general attributes shared with other public figures (i.e. a common occupation).

\section{Method}

\section{Participants}

Considering the cultural sensitivity of the experimental task, all participants were required to be French-speaking, over 55 years old and to have lived at least 40 years in the province of Quebec. Major exclusion criteria were a history of neurological or psychiatric disorder (other than aMCI or AD), alcoholism or substance abuse or general anesthesia in the last six months. The study was approved by the Research Ethics Board of the Centre Hospitalier de l'Université de Montréal (CHUM) and of the Institut universitaire de gériatrie de Montréal (IUGM). All participants provided written informed consent before taking part in the study and received a financial compensation. 
Three groups were included in the study: 20 aMCI patients, 20 mild probable AD patients and 20 healthy controls, matched for age and education. The control group was recruited through the IUGM research center, but one participant was excluded on the basis of his neuropsychological test results. Both patient groups were referred by a team of trained neurologists, geriatricians and clinical neuropsychologists from the Geriatric Clinic of the CHUM or the Memory Clinic of the IUGM.

Patients' diagnosis was established based on the National Institute on Aging-Alzheimer's Association (NIA-AA) recommendations. Thus, for aMCI diagnosis, most recent MCI core clinical criteria were applied (Albert et al., 2011). Criteria included a cognitive concern reflecting a change over time in memory, expressed by the patient, an informant or a clinician. This memory complaint was corroborated by an objective memory impairment on neuropsychological measures of episodic memory (i.e. a performance of 1.5 standard deviations or more below the normal mean on at least two standardized tests). Every aMCI participant presented independent functioning in activities of daily living as assessed during a clinical interview. They also failed to meet diagnostic criteria for dementia. For AD diagnosis, all patients met criteria for dementia. Moreover, they all presented an insidious onset of symptoms, with a predominant amnestic presentation, and a clear-cut history of worsening of cognition (McKhann et al., 2011). All AD patients were presenting the sporadic form of $\mathrm{AD}$ and were in the early stage of the disease.

\section{Neuropsychological Assessment}

All participants underwent a comprehensive neuropsychological assessment to confirm that they were correctly assigned to each group. First, two cognitive screening instruments were used to estimate global cognitive functioning: the Mini-Mental State Examination (MMSE; Folstein, Folstein, \& McHugh, 1975) and the Montreal Cognitive Assessment (MoCA; Nasreddine et al., 
2005). Then, various neuropsychological tests were used to measure language, attention, shortterm and working memory, visuoperceptual and visuoconstructional abilities, episodic memory, semantic memory and executive functions.

Language was evaluated with a 30-item version of the Boston Naming Test (Kaplan, Goodglass, \& Weintraub, 1983; Seni et al., 2010) and a verbal fluency test (phonemic and semantic fluency; Cardebat, Doyon, Puel, Goulet, \& Joanette, 1990).

A cancellation test was used to measure selective visual attention (The Bells test; Gauthier, Dehaut, \& Joanette, 1989). Short-term and working memory was assessed through forward and backward digit span (Wechsler, 2000).

Primary visuoperceptual processing was evaluated with the Judgment of Line Orientation test (Benton, Varney, \& Hamsher, 1978). The Clock Drawing test (Rouleau, Salmon, Butters, Kennedy, \& McGuire, 1992) and the copy of the Rey-Osterrieth complex figure (Rey, 1970) were used to assess visuoconstructional abilities.

Verbal episodic memory was evaluated with story A recall from the Logical Memory subtest of the Wechsler Memory Scale (WMS-III; Wechsler, 2001) and two word-list memory tests : the RL/RI 16 free and cued recall test (Van der Linden et al., 2004) and the Rey Auditory Verbal Learning Test (Estevez-Gonzalez, Kulisevsky, Boltes, Otermin, \& Garcia-Sanchez, 2003; Rey, 1964). Two tests of visual episodic memory were also used: the DMS-48, a visual delayed matching-to-sample task (Barbeau et al., 2004), and the immediate and delayed recall of the ReyOsterrieth complex figure (Rey, 1970). Semantic memory was evaluated with the Pyramids and Palm Tree test (Howard \& Patterson, 1992) and the Information subtest of the Wechsler Adult Intelligence Scale (WAIS-III; Wechsler, 2000). 
Finally, executive functions were assessed with the Trail Making Test (Reitan, 1955) and the Color-Word Interference subtest of the Delis-Kaplan Executive Function System (D-KEFS;

Delis, Kaplan, \& Kramer, 2001).

\section{Famous Names Test}

The Famous names test was devised for the current study and assessed knowledge about 20 famous persons from two different periods. Each famous name was displayed along with two multiple choice questions. The first question assessed general knowledge (e.g. What was the occupation of John F. Kennedy? (a) show business, (b) sports, (c) politics, (d) sciences). The second question assessed more specific knowledge (e.g. How did John F. Kennedy die? (a) In a car accident, (b) he was murdered, (c) from cancer, (d) from suicide). All names and questions were presented in large font and participants had unlimited time to answer. One point was awarded for each correct answer and a maximum score of 40 points could be reached.

Half of the celebrities were famous between 1960 and 1975 (remote famous names) and half were famous between 1990 and 2005 (recent famous names). Also, for each time period, half of the famous persons only briefly achieved fame. They had been out the public eye and were unlikely to have appeared in the media since then (transient fame). The other half consisted of famous persons with long-lasting fame. They were still famous nowadays and information about them had been presented in the media on a regular basis over time (enduring fame).

Famous stimuli were selected using a procedure similar to the one used by Douville et al. (2005) and Langlois et al. (2016). A preliminary study was thus conducted with 35 healthy elderly $(M=72.2$ years, $S D=7.2$ years, $60-85$ years $)$ and 320 young participants $(M=24.1$ years, $S D=2.9$ years, $19-30$ years). An initial set of more than a hundred famous names was presented to them, along with one general and one specific semantic question for each name. 
Those famous names referred to Quebec or worldwide public figures from various fields (e.g. politicians, athletes, entertainers, criminals, scientists, newsreaders, actors, singers). In order to ensure that these names were known in the target population and to confirm the nature of their fame, the following criteria were applied, which resulted in a final selection of 20 famous names (see Appendix A):

- Remote enduring names consisted of five celebrities who became famous between 1960 and 1975 and were still well-known nowadays. Thus, every participant, old or young, was likely to have acquired information about these persons. Consequently, these names had to be correctly identified on both, general and specific, multiple-choice questions by more than $80 \%$ of all participants.

- Recent enduring names consisted of five celebrities who became famous between 1990 and 2005 and still appeared frequently in the current media. As was the case for the remote enduring names, recent enduring names also had to be correctly identified by more than $80 \%$ of all participants.

- Remote transient names consisted of five celebrities who briefly achieved fame between 1960 and 1975, but had been out of the public eye since then. Because information about these famous persons had not been frequently covered in the media for a few decades, only participants who had lived during the 60s-70s could have acquired that information. Consequently, these names had to be correctly identified by more than $80 \%$ of older participants, but no more than $35 \%$ of younger participants.

- Recent transient names consisted of five celebrities who became famous between 1990 and 2005 and were correctly identified by more than $80 \%$ of both younger and older participants. Indeed, younger were as likely as older participants to have been exposed to 
information about these famous persons. Recent transient names remain, however, different from recent enduring names by the ephemeral nature of their fame and their absence in the current media.

\section{Statistical Analysis}

Data analyses were conducted using SPSS version 23 software. The level of statistical significance was set at $p<0.05$ for all statistical tests. Normality of the distribution was confirmed through examination of skewness and kurtosis indexes (Kline, 1998).

Firstly, differences between the three groups in terms of age, education and neuropsychological scores were analyzed using one-way analyses of variance (ANOVA). When required, Tukey tests were conducted for post-hoc comparisons. A chi-square test was also performed to examine the proportion of men and women in each group.

Secondly, different analyses were conducted to evaluate groups' performances on the Famous names test. Accuracy was determined by computing the percentage of correct answers to each variable of the Famous names test. A one-way ANOVA was performed to examine performance of the three groups on the task's total score. Mixed between-within subjects repeated measures ANOVAs were then conducted in order to examine the main effects and interactions between group performances (controls, aMCI, AD) across the two periods (remote and recent) for both enduring and transient famous names. Tukey tests were used for post-hoc comparisons. Temporal gradients were also explored among each group through paired-sample ttests. The accuracy of scores from the remote period was compared to the accuracy of scores from the recent period. 
Finally, the influence of specificity of semantic processing on performance was explored through a mixed between-within subjects repeated measures ANOVA comparing accuracy of the three groups on general and specific questions. Several separate mixed 2 X 3 ANOVAs were also conducted for in-depth analyses of each group performances according to the period, the type of fame and the specificity of semantic processing. Again, Tukey tests were used for posthoc comparisons.

\section{Results}

\section{Demographic and Neuropsychological Data}

Demographic and neuropsychological data are presented in Table 1. The three groups did not significantly differ in terms of age, gender or education. As expected, however, significant differences were found on measures of global cognitive functioning. AD patients obtained significantly lower MMSE scores than controls and aMCI patients, while those two groups did not differ from each other. In contrast, all three groups differed significantly from one another on their MoCA scores. This discrepancy between the two screening instruments is not surprising, considering the greater sensitivity of the MoCA over the MMSE in detecting aMCI (Nasreddine, et al., 2005).

Moreover, as expected, aMCI patients differed significantly from controls on almost all episodic memory measures. Deficits on some measures of semantic memory, working memory and executive functions were also found. On the other hand, severe impairments were found in AD patients on all neuropsychological functions.

(insert Table 1 here) 


\section{Famous Names Test}

A significant difference was found between the three groups on the Famous names test total score $\left(F(2,56)=20.42, p<.001\right.$, eta $\left.^{2}=.42\right)$. Indeed, aMCI patients were significantly more impaired than controls (percent correct: $81.00 \pm 13.19$ vs $93.02 \pm 7.00, p<.01$ ), but performed better than AD patients (percent correct: $71.00 \pm 11.04, p<.05$ ). In addition, specific differences arose when performance was examined as a function of the type of fame and period.

Enduring famous names. Analysis of accuracy scores for enduring names revealed significant main effects of the group $\left(F(2,56)=13.70, p<.001\right.$, partial eta $\left.^{2}=.33\right)$ and period $\left(F(1,56)=59.23, p<.001\right.$, partial eta $\left.^{2}=.51\right)$ as well as a significant group $\mathrm{X}$ period interaction $\left(F(2,56)=8.11, p<.01\right.$, partial eta $\left.^{2}=.22\right)$. In regard to remote enduring names, aMCI patients performed like controls $(p=.92)$ and both groups were significantly better than the AD group ( $p$ $<.05)$. However, in regard to recent enduring names, the aMCI group performed like the AD group ( $p=.08)$ and was significantly impaired compared to the control group $(p<.01)$. Accuracy for enduring names in each group is shown in Figure 1.

In order to determine if a temporal gradient emerged, comparisons of accuracy scores between remote and recent enduring names were also carried out for each group. A temporal gradient was found in both aMCI and AD groups $\left(t(19)=5.39, p<.001\right.$, eta $^{2}=.60$ and $t(19)=$ $6.09, p<.001$, eta $^{2}=.66$, respectively), because their performance with remote names was better than with recent ones. However, no temporal gradient was observed in the control group ( $p=$ $.19)$.

(insert Figure 1 here) 
Transient famous names. On the other hand, analysis of accuracy scores for transient names only revealed a main effect of group $\left(F(2,56)=19.63, p<.001\right.$, partial eta $\left.{ }^{2}=.41\right)$. Thus, aMCI patients remained significantly impaired compared to controls, regardless of time period (remote transient: $p<.05$; recent transient: $p<.01)$. Moreover, their performance was similar to the AD patients regarding remote transient names $(p=.20)$, but remained slightly better concerning recent transient names $(p<.05)$. Accuracy for transient names in each group is shown in Figure 1. Moreover, no temporal gradient was found among the three groups, since their performance always remained similar across periods (aMCI: $p=.72$, AD: $p=.14$, controls: $p=.08$ ).

It is noteworthy to mention that the Famous names test mainly comprised national famous figures from Quebec (ex. Gilles Vigneault), and to a lesser extent some internationally famous figures (ex. John F. Kennedy). In order to determine if the international vs. national status of famous figures had an impact on the results, exploratory analyses were carried out. Thus, the international names were removed from the data set and separate analyses were carried out only on the national famous names. A similar profile was obtained, indicating that this factor did not influence the results. Indeed, accuracy scores for enduring national names still revealed a significant group X period interaction $\left(F(2,56)=6.39, p<.01\right.$, partial eta $\left.{ }^{2}=.19\right)$, where the aMCI patients performed like controls with items from the remote period $(p=.40)$, but performed like the $\mathrm{AD}$ patients with items from the recent period $(p=.07)$. Accuracy scores for transient national names also showed the same main effect of group $(F(2,56)=16.83, p<.001$, partial eta ${ }^{2}=.38$ ), where both patients groups were significantly impaired compared to the control group for the remote period (aMCI: $p<.05$; AD: $p<.001$ ) as well as the recent period (aMCI: $p<.01$; AD: $p<.001$ ). Finally, even without international famous names, the profiles 
regarding temporal gradients remained unchanged. A significant difference between remote and recent names was found among aMCI and AD patients with enduring names $(p<.001$ for both groups), but not with transient ones (aMCI: $p=.87$; $\mathrm{AD}: p=.36$ ), while no temporal gradient was observed in the control group (enduring national names: $p=.38$, transient national names: $p$ $=.18)$.

Specificity of semantic processing (general vs specific knowledge). In the Famous names test, two questions were used to assess semantic knowledge about public figures: one tapping general knowledge (i.e. occupation) and another one tapping specific knowledge (i.e. unique biographical information). In order to explore how the specificity of semantic processing influenced performance, accuracy on these two types of questions was compared among the three groups.

The analysis showed significant main effects of $\operatorname{group}\left(F(2,56)=20.42, p<.001\right.$, partial eta ${ }^{2}=$ $.42)$ and specificity of semantic processing $\left(F(1,56)=37.51, p<.001\right.$, partial eta $\left.^{2}=.40\right)$, as well as a significant group $\mathrm{X}$ specificity of semantic processing interaction $(F(2,56)=7.45, p<.01$, partial eta $\left.{ }^{2}=.21\right)$. Indeed, both aMCI and AD patients performed significantly better on general knowledge questions than on those assessing more specific knowledge $(p<.01$ and $p<.001$, respectively). No such difference was observed among controls $(p=.11)$. Results are shown in Figure 2.

(insert figure 2 here) 
Furthermore, the influence of the specificity of semantic processing was explored in association with the type of fame and the period. Patterns of performance on specific and general knowledge questions were analyzed separately.

Questions assessing specific knowledge. Overall, the analysis of specific questions showed a profile similar to the results presented above. With enduring names, a significant period X group interaction $\left(F(2,56)=4.33, p<.05\right.$, partial eta $\left.^{2}=.13\right)$ was found, in addition to main effects of period $\left(F(1,56)=23.15, p<.001\right.$, partial eta $\left.^{2}=.29\right)$ and group $(F(2,56)=11.99, p$ $<.001$, partial eta $\left.{ }^{2}=.30\right)$. Indeed, aMCI patients performed like controls in regard to enduring remote names $(p=.92)$, but performed similarly to AD patients regarding enduring recent names $(p=.12)$. AD patients remained significantly impaired compared to controls for both periods (remote enduring names: $p<.05$; recent enduring names: $p<.001$ ).

With transient names, results only revealed a significant main effect of group $(F(2,56)=$ $19.63, p<.001$, partial eta $\left.{ }^{2}=.41\right)$. Performance of aMCI patients was impaired for both periods when compared to controls (remote transient names: $p<.05$; recent transient names: $p<.01$ ). The aMCI group was also slightly better than the AD group in regard to recent names $(p<.05)$, but not remote ones $(p=.12)$

Questions assessing general knowledge. On the other hand, the analysis of general knowledge questions revealed few differences between the three groups, all circumscribed to the recent period. With enduring names, a significant period $\mathrm{X}$ group interaction was found $(F(2,56)$ $=5.62, p<.01$, partial eta $\left.{ }^{2}=.17\right)$, in addition to main effects of period $(F(1,56)=54.76, p<.001$,

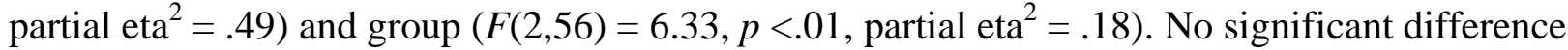
was found between the three groups concerning names from the remote period $(p=.38)$. For the 
recent period however, aMCI patients were significantly impaired compared to controls $(p<.05)$ and performed similarly to AD patients $(p=.23)$.

Concerning transient names, significant main effects of period $(F(1,56)=4.96, p<.05$, partial eta $\left.^{2}=.08\right)$ and group $\left(F(2,56)=8.72, p<.01\right.$, partial eta $\left.{ }^{2}=.24\right)$ were found, but no significant interaction was found $(p=.34)$. Again, no significant difference was found between the three groups regarding names from the remote period $(p=.11)$, and performance for the recent time period was significantly impaired in aMCI patients compared to controls $(p<.01)$, but similar to the $\operatorname{AD}$ group $(p=.13)$.

In summary, the present study assessed semantic memory using a test of famous person knowledge. Results revealed that the aMCI group showed significant semantic deficits, although less severe than in the $\mathrm{AD}$ group, and that performance was influenced by several specific factors. For instance, both the type of fame (enduring vs. transient) and the period (remote vs. recent) elicited different response patterns among patients and their deficits were more prominent when questions assessed specific knowledge rather than broader general knowledge.

\section{Discussion}

The aim of this study was to provide a detailed account of the nature of the early breakdown of famous person knowledge in aMCI and AD. Due to the conflicting results previously reported in the literature, a specific effort was made to consider both the onset of fame as well as the lasting nature of the fame (i.e. the effect of repeated exposure). A detailed protocol was devised to assess semantic knowledge for famous persons which controlled for the period when semantic information had been encoded as well as the frequency of exposure in the media. 
Global performance of aMCI and AD patients on the Famous names tests was significantly impaired compared with a control group matched for age, sex and education. As expected, semantic deficits were less important in the aMCI group than in the AD group. These results corroborate those of previous studies that have shown semantic deficits in aMCI and AD, especially on tasks assessing famous person knowledge (Ahmed, et al., 2008; Borg, et al., 2010; Dudas, Clague, Thompson, Graham, \& Hodges, 2005; Estevez-Gonzalez, et al., 2004; Joubert, et al., 2008; Thompson, et al., 2002; Vogel, et al., 2005).

Furthermore, the pattern of semantic impairment varied as a function of the enduring vs. transient nature of fame. When knowledge about famous people frequently exposed in the media over the years (enduring names) was assessed, a temporal gradient favouring remote over recent person-based semantic knowledge was found in both aMCI and AD. Moreover, no significant difference in terms of accuracy was found between the aMCI and control groups in regard to remote enduring famous names, while a significant difference was found for recent enduring names. AD patients in turn showed impaired knowledge for both recent and remote enduring famous names.

In contrast, when famous persons were only briefly exposed in the media (transient names), the relative preservation of remote knowledge over recent knowledge was not found in aMCI and AD. In fact, aMCI and AD patients were always impaired when compared to the control group, regardless of the period, and no particular temporal gradient emerged. These results were also not influenced by the national vs. international standing of the famous persons.

Previous studies have produced conflicting results about the existence of a temporal gradient in aMCI and AD. Some studies have shown greater impairment for recently acquired knowledge than for more distant knowledge (Bizzozero, et al., 2009; Delazer, et al., 2003; Greene \& 
Hodges, 1996; Hodges, et al., 1993; Seidenberg, et al., 2009), while other studies failed to identify a temporal gradient and rather showed similar impairment across all periods (Barbeau, et al., 2012; Leyhe, et al., 2010; Thompson, et al., 2002). The current results highlight the importance of considering other variables than the age of memories and are in line with those of Muller et al. (2014), who found that frequently retrieved historical events and facts appeared to be better protected against early deterioration in AD. Indeed, retrieval of semantic knowledge about historical events did not depend on the age of the memories, but rather on how frequently these memories had been retrieved, based on subjective judgments made by the patients. Thus, information that had been re-encoded multiple times during a lifetime was associated with better recall.

To date, only one other study has examined the impact of both time and type of fame on semantic performance in aMCI. Similar to the current results, Seidenberg et al. (2009) found that retrieval of semantic knowledge was worse for recent famous names than for remote or enduring ones. However, it is worth mentioning that there were important methodological differences between the two studies.

First, Seidenberg et al. (2009) used a famous name recognition task that mainly relied on familiarity judgments (i.e. distinguishing famous names from unfamiliar names), which, in our view, only provides a superficial assessment of semantic knowledge. Accuracy was slightly lower and reaction times were slower for recent names than for remote and enduring names. However, no significant main effect of group was obtained between aMCI and control groups, which was attributed to ceiling effects, and no significant group by time interaction was found, making these results somewhat difficult to interpret. On the other hand, their second task involved free recall of semantic knowledge about famous people in response to four probes 
(occupation, known accomplishments, associated individuals/events and history/background information). Results showed that aMCI patients reported less semantic knowledge than controls and that they produced slightly more information about enduring names than about recent or remote names. Although this type of task allows a deeper assessment of semantic knowledge, it relies on effortful semantic search, manipulation and retrieval processes often found to be affected in normal and pathological aging (Joubert et al., 2010).

In the present study, we chose to use a multiple choice semantic recognition task. In our view, this experimental procedure seemed more appropriate to an aMCI and AD population, since it allowed a deeper and more specific assessment of semantic knowledge, while reducing the executive load required to process semantic information (Hodges et al., 1993; Joubert et al., 2010). These are important elements to consider, since impairment in tasks requiring intentional access to semantic knowledge has been documented in aMCI (Duong, Whitehead, Hanratty, \& Chertkow, 2006). In the same line, conceptual priming tasks may also be particularly useful in demonstrating more central semantic disturbances. For instance, Brambati et al. (2012) recently showed that aMCI patients had degraded semantic representations of famous persons using a semantic priming task that did not require intentional access to semantic concepts.

Also, although most studies use photographs of famous faces (Ahmed et al., 2008; EstevezGonzalez et al., 2004; Joubert et al., 2008; Thompson et al., 2002; Vogel et al., 2005), presentation of famous names was preferred here. First, the fact that faces are prone to changes in their physical appearance over time may complicate their identification, while names always remain stable (Haslam, Kay, Hanley, \& Lyons, 2004). A recent study also suggested that AD patients have mild deficits in higher-level visual processes, which may alter their perception of individual faces (Lavallee et al., 2016). Those subtle visuoperceptual impairments may thus 
exacerbate their semantic deficits when stimuli are presented in the visual modality. Finally, we wanted to compare the results of the Famous Names test with another test, which assesses memory for public events (Langlois et al., 2016). For uniformity purposes, we chose to present famous stimuli of both tests in the verbal modality.

The current study also revealed that aMCI and $\mathrm{AD}$ patients presented a weaker performance on questions assessing specific knowledge (vs. general) about famous people. Early deterioration of distinctive attributes of semantic concepts in $\mathrm{AD}$ has been reported in previous studies (Garrard, Lambon Ralph, Patterson, Pratt, \& Hodges, 2005; Giffard et al., 2002; Laisney et al., 2011; Rogers \& Friedman, 2008). Our results show that distinctive attributes are also more vulnerable in aMCI. Since questions tapping specific biographical knowledge appear to be more sensitive in revealing semantic impairment in aMCI and AD patients, their use should be encouraged in future studies.

These findings may be interpreted considering the inherent structure of semantic memory. Indeed, according to hierarchical frameworks, the current results may reflect a progressive degradation of semantic concepts starting from specific to subordinate and ultimately to superordinate knowledge (Collins \& Quillian, 1969; Warrington, 1975). Connectionist models, on the other hand, posit that semantic memory lies on a widely distributed network of semantic features, where category structure is based on similarity. Thus, attributes shared by several concepts might be more robust to semantic damage than specific or unique attributes, because of their greater overlap with similar concepts distributed in semantic memory (Devlin, Gonnerman, Andersen, \& Seidenberg, 1998; McRae, de Sa, \& Seidenberg, 1997; Tyler \& Moss, 2001). Classic cognitive models of face processing consider that the identification of known persons occurs through the activation of face recognition units (FRUs), which in turn activate person 
identity nodes (PINs) that provide access to identity-specific semantic information necessary for the correct identification and name retrieval of a familiar person (Bruce and Young, 1986). More recent studies have provided new insights concerning the cognitive architecture of famous person knowledge (Wiese, 2011). In fact, there is evidence suggesting that its organization may be different from that of other categories of knowledge and that it may rely upon different organizing principles. Firstly, person knowledge may depend upon a categorical organization. Famous persons may be recognized based on commonly shared properties such as occupation (e.g. Brad Pitt and George Clooney are both Hollywood actors). More importantly, however, famous person knowledge may also be organized according to associative relationships and representations for persons may be stored in associative networks (e.g. Victoria and David Beckham are related to each other because they are a married couple, but they don't share the same occupation; for a review on this topic, see Wiese, 2011). In the current study, general questions concerned the occupation of famous persons, while specific questions referred to specific biographical knowledge about celebrities. It is possible that greater impairment in patients found for specific questions may reflect greater vulnerability and decline of associative semantic relations relative to categorical relations (general questions). Greater impairment on specific questions may also reflect greater vulnerability to disease of the idiosyncratic knowledge that is being assessed (i.e. specific questions refer to knowledge that is unique to an individual).

\section{Theoretical models of memory consolidation}

The present findings appear to be partly consistent with current theoretical models of remote memory. According to the standard model of consolidation (Squire \& Alvarez, 1995), the hippocampal complex (HC) and medial temporal lobes (MTL) are believed to temporarily store and retrieve both semantic and episodic memories, until long-term consolidation happens 
through the formation of memory traces in neocortical and extra-hippocampal structures.

Disruption of mesial temporal lobe structures, observed in aMCI and early AD (Braak \& Braak, 1991; Delacourte et al., 1999; Guillozet, Weintraub, Mash, \& Mesulam, 2003; Mitchell et al., 2002; Van Hoesen, Hyman, \& Damasio, 1991), would thus lead to impaired retrieval and recall of recent information, but spared memory for remote information which gradually become independent from these regions. Therefore, this theoretical model is coherent with the temporal gradient found among patients when enduring knowledge was assessed, but in our view fails to explain the absence of a temporal gradient with the use of transient material.

On the other hand, the multiple trace theory (Moscovitch, Nadel, Winocur, Gilboa, \& Rosenbaum, 2006; Moscovitch et al., 2005), posits that autobiographical episodes are always mediated by the HC and that a new MTL-neocortical trace is created each time an episodic memory is retrieved. A process of semanticization is also proposed to explain how common information is extracted from multiple episodes and is integrated with pre-existing knowledge to produce semantic memory. Knowledge becomes progressively independent of the hippocampal complex and increasingly reliant on neocortical structures. In the current study, knowledge about enduring famous persons from a remote period, who benefited from the most frequent exposure in the media over the years, was better preserved among patients than knowledge about persons whose fame was only transient. We can presume that semantic information about enduring stimuli relies on stronger and more widely distributed memory traces, whereas knowledge about transient famous persons who only benefited from brief public exposure rests on weaker and scarce memory traces, making them more vulnerable to brain damage.

It has also been argued that the temporal gradient found in some studies reflected the presence of anterograde amnesia during the most recent time periods (Meeter, Eijsackers, \& 
Mulder, 2006; Seidenberg, et al., 2009). For example, on a test of famous public events involving three different decades, Meeter et al. (2006) found that AD patients showed a weak, yet significant, temporal gradient, whereby their recall was slightly better for remote than for more recent events. However, this temporal gradient did not remain significant when the most recent period was excluded from the analysis. The authors suggested that their results may have been influenced by the presence of anterograde memory deficits in the disease, affecting the most recent years, rather than reflecting a true gradient in retrograde amnesia. In order to circumvent this potential limitation, we only assessed person-based semantic knowledge that was presumably acquired before disease onset. Even though it is impossible to date with precision the exact moment when the first symptoms appeared, we tried to reduce this possible bias of anterograde amnesia by excluding names of persons who became famous after 2005 and by using a large time frame for the recent period (1990-2005). Despite the attempts to control for this aspect, a temporal gradient was still found among aMCI and AD patients for enduring famous persons, indicating that mechanisms that are distinct from the anterograde memory impairment are responsible for the semantic deficits found in this population. Those observations are in line with Smith et al. (2014), who found an extended retrograde amnesia among aMCI patients that was disproportionate in relation to their anterograde amnesia.

Although results of the current study can be interpreted in light of current models of memory function and MTL damage, it should be noted that lesions extending beyond MTL structures are also present in aMCI. This may include for instance neocortical regions such as the anterior temporal lobes (ATL). For instance, Joubert, et al. (2010) found that impaired performance of aMCI patients in various semantic tasks was associated with reduced gray matter volume in the ATL and in the inferior prefrontal cortex, which are regions typically associated with the 
semantic network. Semantic deficits in aMCI were also found to be correlated with damage to a network of anteromesial temporal structures including the entorhinal/perirhinal cortex, the temporopolar cortex, the anterior fusiform gyrus and the anterior hippocampal region (Barbeau, et al., 2012). Thus, further neuroimaging studies are clearly needed in order to gain a better understanding of the neural basis of semantic impairment in aMCI and AD, particularly when considering specific variables such as the time and the enduring vs. transient nature of the semantic knowledge acquired.

Furthermore, recent work showed similar patterns of impairment in aMCI and AD on a test assessing memory for public events (Langlois, et al., 2016). Indeed, a better performance was observed for enduring events compared with transient events, again supporting the idea that frequent repetition of information over time and broad media exposure promotes stronger memory traces that are more resistant to neurodegenerative damage. In contrast to our results, however, this study showed no clear temporal gradient across four time periods (1960-1975; 1976-1990; 1991-2005; 2006-2011). It is possible that inherent differences in the organization of knowledge between public events and famous persons may account for those discrepancies. Famous public events occur in a specific time and place, they only occur once and they usually do not evolve over time. On the other hand, famous public figures are typically much more dynamic because they change and evolve over time, especially those who benefit from longlasting media exposure. Enduring famous persons who achieve new accomplishments (e.g. an actor who appears in a new movie) requires knowledge about them to be regularly updated. Famous people may also be more socially important and relevant to us. Thus, these differences may conceivably account for some of the differences in the patterns of memory impairment that we observed in the present study and in the study by Langlois et al. (2016). 
In conclusion, the present study contributes to further understanding of the nature of semantic impairment in aMCI and AD. The findings underline the importance of considering the transient vs. enduring nature of fame, together with the period of celebrity, in order to better understand the pattern of retrograde semantic memory impairment. They also suggest that frequently rehearsed knowledge may strengthen memory traces. Finally, results of the current study suggest that assessing specific knowledge about famous persons, rather than more general knowledge (such as occupation) may be more sensitive in revealing semantic deficits in these populations. 


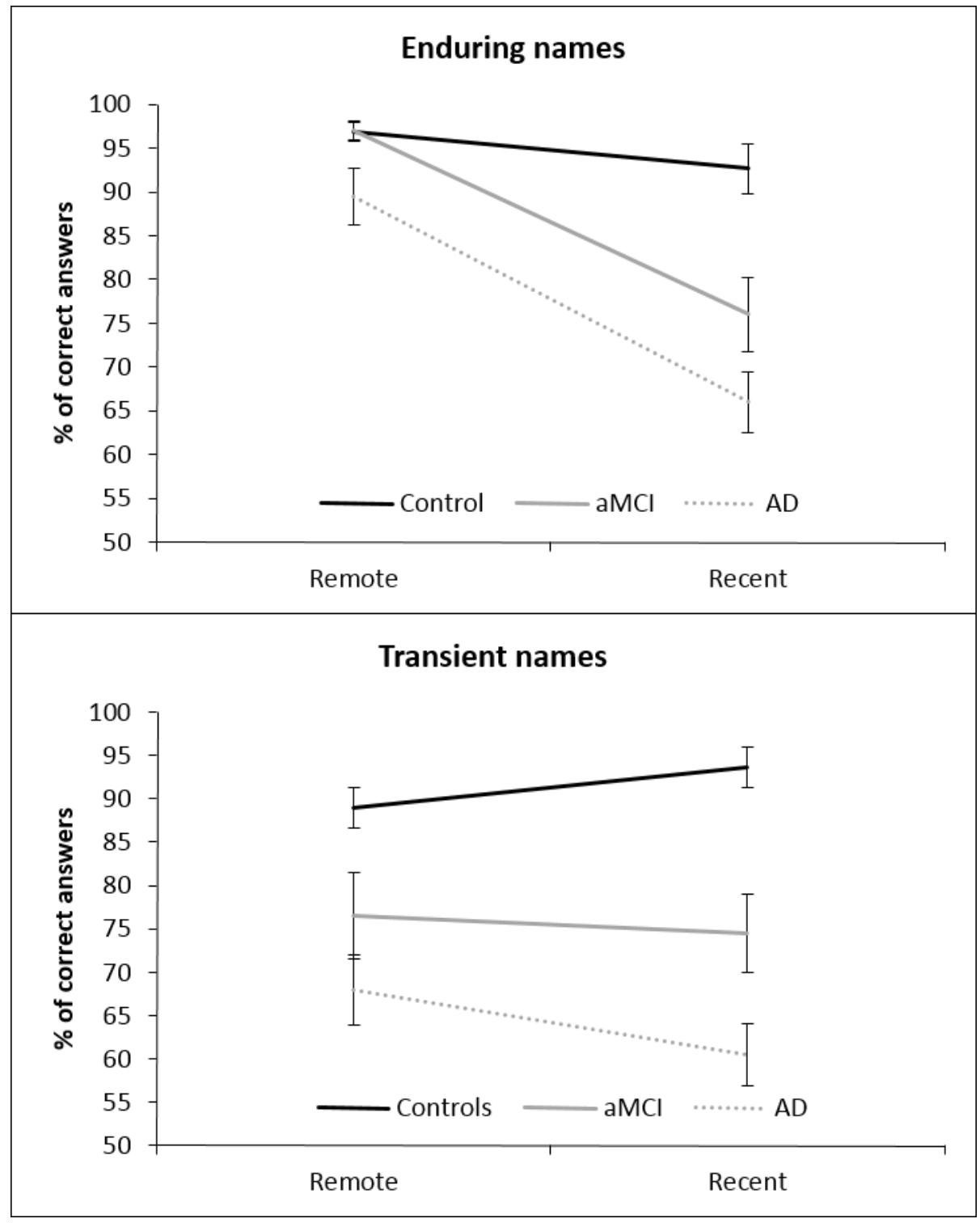

Figure 1. Accuracy for enduring and transient famous names for control, aMCI and AD groups. The error bars represent the standard error of the mean. 


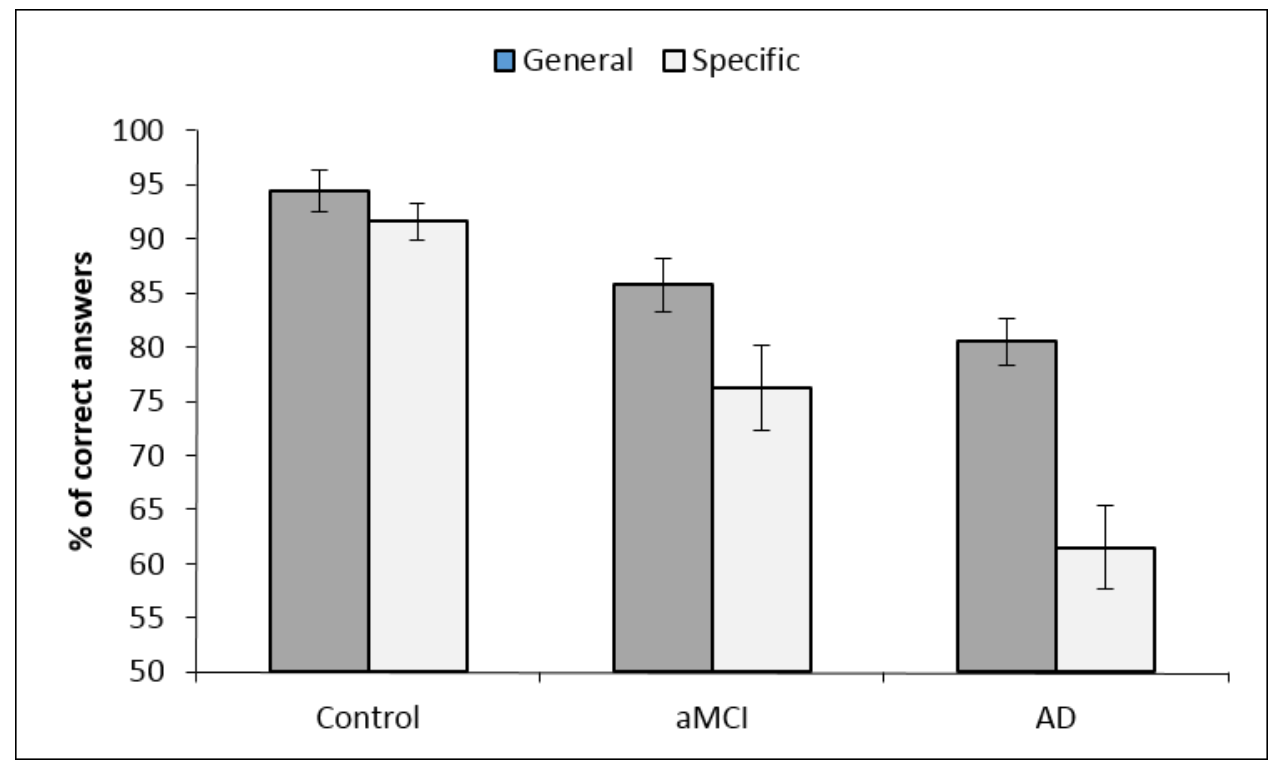

Figure 2. Performance on general and specific knowledge questions for the control, aMCI and AD groups. The error bars represent the standard error of the mean. 
Table 1

Demographics and Neuropsychological Results

\begin{tabular}{|c|c|c|c|c|}
\hline Measures & Controls & aMCI & $\mathrm{AD}$ & $p$ \\
\hline \multicolumn{5}{|l|}{ Demographics } \\
\hline Age (years) & $73.9(8.5)$ & $76.9(6.5)$ & $77.6(6.0)$ & .240 \\
\hline Education (years) & $14.6(3.7)$ & $14.5(4.3)$ & $12.3(4.5)$ & .156 \\
\hline Men/Women & $6 / 13$ & $6 / 14$ & $7 / 13$ & .942 \\
\hline \multicolumn{5}{|l|}{ Global cognitive functioning } \\
\hline $\operatorname{MMSE}(/ 30)$ & $28.8(1.1)$ & $27.7(2.3)$ & $25.2(2.0)^{b, c}$ & $<.001$ \\
\hline $\operatorname{MoCA}(/ 30)$ & $28.1(1.4)$ & $25.8(2.4)^{\mathrm{a}}$ & $20.1(3.1)^{b, c}$ & $<.001$ \\
\hline \multicolumn{5}{|l|}{ Language } \\
\hline Boston Naming Test (/30) & $28.8(1.4)$ & $27.5(2.7)$ & $25.8(3.9)^{b}$ & $<.01$ \\
\hline Phonemic fluency $-\mathrm{P}$ in $2 \mathrm{~min}$ & $23.1(6.4)$ & $20.9(5.0)$ & $15.4(4.8)^{b, c}$ & $<.001$ \\
\hline Semantic fluency - animals in 2 min & $29.4(6.1)$ & $23.2(7.0)^{\mathrm{a}}$ & $17.8(4.7)^{b, c}$ & $<.001$ \\
\hline \multicolumn{5}{|l|}{ Attention / working memory } \\
\hline Bells test (sec) & $146.6(49.9)$ & $143.0(47.0)$ & $157.3(88.1)$ & .771 \\
\hline Digit span forward WAIS-III & $6.1(0.9)$ & $6.1(1.0)$ & $5.6(1.0)$ & .177 \\
\hline Digit span backward WAIS-III & $5.2(1.0)$ & $4.4(0.9)^{\mathrm{a}}$ & $3.5(1.0)^{b, c}$ & $<.001$ \\
\hline \multicolumn{5}{|c|}{ Visuoperceptual / visuoconstructional abilities } \\
\hline JLO test $(/ 30)$ & $23.4(4.2)$ & $21.9(4.2)$ & $19.4(5.6)^{b}$ & $<.05$ \\
\hline Clock Drawing test (/10) & $9.1(1.5)$ & $8.6(2.0)$ & $8.0(1.8)$ & .169 \\
\hline ROCF - Copy (/36) & $31.0(3.1)$ & $31.1(3.6)$ & $27.7(5.5)^{b, c}$ & $<.05$ \\
\hline \multicolumn{5}{|l|}{ Episodic memory } \\
\hline LM WMS-III - Delayed recall (/25) & $17.5(3.8)$ & $13.7(3.6)^{\mathrm{a}}$ & $4.0(3.6)^{b, c}$ & $<.001$ \\
\hline \multicolumn{5}{|l|}{ RL/RI16 } \\
\hline Delayed free recall (/16) & $12.0(2.6)$ & $7.0(2.0)^{\mathrm{a}}$ & $1.8(2.0)^{\mathrm{b}, \mathrm{c}}$ & $<.001$ \\
\hline Delayed total recall (/16) & $15.5(0.9)$ & $14.1(1.5)$ & $7.9(4.2)^{b, c}$ & $<.001$ \\
\hline RAVLT - Delayed recall (/15) & $11.6(2.7)$ & $5.8(3.3)^{a}$ & $1.3(1.7)^{b, c}$ & $<.001$ \\
\hline DMS-48 - 1-hour delayed recall (/48) & $95.8(5.5)$ & $91.6(7.9)$ & $73.7(13.9)^{b, c}$ & $<.001$ \\
\hline ROCF - Delayed recall (/36) & $16.1(5.3)$ & $11.2(5.9)^{\mathrm{a}}$ & $5.6(4.8)^{b, c}$ & $<.001$ \\
\hline \multicolumn{5}{|l|}{ Semantic memory } \\
\hline Pyramids and Palm Tree test (/52) & $50.3(1.6)$ & $49.4(2.0)$ & $48.2(2.9)^{b}$ & $<.05$ \\
\hline Information WAIS-III (/28) & $20.6(4.8)$ & $16.1(4.9)^{\mathrm{a}}$ & $13.0(5.8)^{b}$ & $<.001$ \\
\hline \multicolumn{5}{|l|}{ Executive functions } \\
\hline \multicolumn{5}{|l|}{ Trail Making Test } \\
\hline Part A (sec) & $42.5(11.6)$ & $47.6(18.6)$ & $58.0(19.0)^{\mathrm{b}}$ & $<.05$ \\
\hline Part B (sec) & $98.3(30.4)$ & $124.6(45.5)$ & $201.4(122.8)^{b, c}$ & $<.001$ \\
\hline \multicolumn{5}{|l|}{ Color-Word Interference D-KEFS } \\
\hline Inhibition (sec) & $65.8(12.4)$ & $76.3(17.5)$ & $94.6(25.0)^{b, c}$ & $<.001$ \\
\hline Inhibition/Switching (sec) & $69.9(14.3)$ & $86.0(23.8)$ & $123.9(65.1)^{b, c}$ & $<.01$ \\
\hline
\end{tabular}

Note. Results are presented in Mean and SD in brackets. All the $p$ values are based on an analysis of variance, except for the proportion of men and women, where a chi-square test was used. 
MMSE= Mini-Mental State Examination; MOCA= Montreal Cognitive Assessment; WAIS-III =

Wechsler Adult Intelligence Scale III; JLO = Judgment of Line Orientation; ROCF = Rey-

Osterrieth complex figure; LM WMS-III = Logical Memory subtest of the Wechsler Memory

Scale III; RAVLT = Rey Auditory Verbal Learning Test; D-KEFS = Delis-Kaplan Executive

Function System

Post-hoc comparisons:

${ }^{\mathrm{a}} \mathrm{p}<0.05$ between control and aMCI groups.

${ }^{\mathrm{b}} \mathrm{p}<0.05$ between control and AD groups.

${ }^{c} \mathrm{p}<0.05$ between aMCI and AD groups. 


\section{References}

Adlam, A.-L. R., Bozeat, S., Arnold, R., Watson, P., \& Hodges, J. R. (2006). Semantic knowledge in mild cognitive impairment and mild Alzheimer's disease. Cortex, 42(5), 675-684. doi: 10.1016/S0010-9452(08)70404-0

Ahmed, S., Arnold, R., Thompson, S. A., Graham, K. S., \& Hodges, J. R. (2008). Naming of objects, faces and buildings in mild cognitive impairment. Cortex, 44(6), 746-752. doi: 10.1016/j.cortex.2007.02.002

Albert, M. S., DeKosky, S. T., Dickson, D., Dubois, B., Feldman, H. H., Fox, N. C., ... Phelps, C. H. (2011). The diagnosis of mild cognitive impairment due to Alzheimer's disease: recommendations from the National Institute on Aging-Alzheimer's Association workgroups on diagnostic guidelines for Alzheimer's disease. Alzheimer's \& Dementia, 7(3), 270-279. doi: 10.1016/j.jalz.2011.03.008

Amieva, H., Le Goff, M., Millet, X., Orgogozo, J.-M., Pérès, K., Barberger-Gateau, P., . . . Dartigues, J.-F. (2008). Prodromal Alzheimer's disease: successive emergence of the clinical symptoms. Annals of Neurology, 64(5), 492-498. doi: 10.1002/ana.21509

Barbeau, E., Didic, M., Joubert, S., Guedj, E., Koric, L., Felician, O., . . Ceccaldi, M. (2012). Extent and neural basis of semantic memory impairment in mild cognitive impairment. Journal of Alzheimer's Disease, 28(4), 823-837. doi: 10.3233/JAD-2011-110989

Barbeau, E., Didic, M., Tramoni, E., Felician, O., Joubert, S., Sontheimer, A., . . Poncet, M. (2004). Evaluation of visual recognition memory in MCI patients. Neurology, 62(8), 1317-1322. doi: 10.1212/01.WNL.0000120548.24298.DB

Benton, A. L., Varney, N. R., \& Hamsher, K. S. (1978). Visuospatial judgment: A clinical test. Archives of Neurology, 35(6), 364-367. doi: 10.1001/archneur.1978.00500300038006 
Bizzozero, I., Lucchelli, F., Saetti, M. C., \& Spinnler, H. (2009). Mild cognitive impairment does entail retrograde amnesia for public events. Journal of Clinical \& Experimental Neuropsychology, 31(1), 48-56. doi: 10.1080/13803390801978864

Borg, C., Thomas-Anterion, C., Bogey, S., Davier, K., \& Laurent, B. (2010). Visual imagery processing and knowledge of famous names in Alzheimer's disease and MCI. Aging Neuropsychology \& Cognition, 17(5), 603-614. doi: 10.1080/13825585.2010.481357

Braak, H., \& Braak, E. (1991). Neuropathological stageing of Alzheimer-related changes. Acta Neuropathologica, 82, 239-259. doi: 10.1007/BF00308809

Brambati, S. M., Peters, F., Belleville, S., \& Joubert, S. (2012). Lack of semantic priming effects in famous person recognition in Mild Cognitive Impairment. Cortex, 48(4), 414-420. doi: 10.1016/j.cortex.2011.04.001

Bruce, V., \& Young, A. (1986). Understanding face recognition. British Journal of Psychology, 77(3), 305-327. doi: 10.1111/j.2044-8295.1986.tb02199.x

Burton, A.M., Bruce, V., \& Johnston, R.A. (1990). Understanding face recognition with an interactive activation model. British Journal of Psychology, 81(Pt 3), 361-380. doi: 10.1111/j.2044-8295.1990.tb02367.x

Cardebat, D., Doyon, B., Puel, M., Goulet, P., \& Joanette, Y. (1990). Évocation lexicale formelle et sémantique chez des sujets normaux. Performances et dynamiques de la production en fonction du sexe, de l'âge et du niveau d'étude. Acta Neurologica Belgica, 90, 207-217.

Clague, F., Graham, K. S., Thompson, S. A., \& Hodges, J. R. (2011). Is knowledge of famous people compromised in mild cognitive impairment? Cognitive \& Behavioral Neurology, 24(3), 134-144. doi: 10.1097/WNN.0b013e318234315a 
Collins, A. M., \& Quillian, M. R. (1969). Retrieval time from semantic memory. Journal of Verbal Learning and Verbal Behavior, 8(2), 240-247. doi: 10.1016/S0022$5371(69) 80069-1$

Delacourte, A., David, J. P., Sergeant, N., Buee, L., Wattez, A., Vermersch, P. M. D., . . Di Menza, C. (1999). The biochemical pathway of neurofibrillary degeneration in aging and Alzheimer's disease. Neurology, 52(6), 1158-1165. doi: 10.1212/WNL.52.6.1158

Delazer, M., Semenza, C., Reiner, M., Hofer, R., \& Benke, T. (2003). Anomia for people names in DAT--evidence for semantic and post-semantic impairments. Neuropsychologia, 4l(12), 1593-1598. doi: 10.1016/S0028-3932(03)00116-7

Delis, D. C., Kaplan, E., \& Kramer, J. H. (2001). Delis-Kaplan Executive Function Scale. San Antonio: Psychological Corporation.

Devlin, J. T., Gonnerman, L. M., Andersen, E. S., \& Seidenberg, M. S. (1998). Category-specific semantic deficits in focal and widespread brain damage: a computational account. Journal of cognitive neuroscience, 10(1), 77-94. doi: 10.1162/089892998563798

Douville, K., Woodard, J. L., Seidenberg, M., Miller, S. K., Leveroni, C. L., Nielson, K. A., . . Rao, S. M. (2005). Medial temporal lobe activity for recognition of recent and remote famous names: an event-related fMRI study. Neuropsychologia, 43(5), 693-703. doi: 10.1016/j.neuropsychologia.2004.09.005

Dudas, R. B., Clague, F., Thompson, S. A., Graham, K. S., \& Hodges, J. R. (2005). Episodic and semantic memory in mild cognitive impairment. Neuropsychologia, 43(9), 1266-1276. doi: 10.1016/j.neuropsychologia.2004.12.005 
Duong, A., Whitehead, V., Hanratty, K., \& Chertkow, H. (2006). The nature of lexico-semantic processing deficits in mild cognitive impairment. Neuropsychologia, 44(10), 1928-1935. doi: 10.1016/j.neuropsychologia.2006.01.034

Estevez-Gonzalez, A., Garcia-Sanchez, C., Boltes, A., Otermin, P., Pascual-Sedano, B., Gironell, A., \& Kulisevsky, J. (2004). Semantic knowledge of famous people in mild cognitive impairment and progression to Alzheimer's disease. Dementia \& Geriatric Cognitive Disorders, 17(3), 188-195. doi: 10.1159/000076355

Estevez-Gonzalez, A., Kulisevsky, J., Boltes, A., Otermin, P., \& Garcia-Sanchez, C. (2003). Rey verbal learning test is a useful tool for differential diagnosis in the preclinical phase of Alzheimer's disease: comparison with mild cognitive impairment and normal aging. International Journal of Geriatric Psychiatry, 18(11), 1021-1028. doi: 10.1002/gps.1010

Folstein, M. F., Folstein, S. E., \& McHugh, P. R. (1975). "Mini-mental state". A practical method for grading the cognitive state of patients for the clinician. Journal of Psychiatric Research, 12(3), 189-198. doi: 10.1016/0022-3956(75)90026-6

Garrard, P., Lambon Ralph, M. A., Patterson, K., Pratt, K. H., \& Hodges, J. R. (2005). Semantic feature knowledge and picture naming in dementia of Alzheimer's type: a new approach. Brain \& Language, 93(1), 79-94. doi: 10.1016/j.bandl.2004.08.003

Gauthier, L., Dehaut, F., \& Joanette, Y. (1989). The Bells Test: A quantitative and qualitative test for visual neglect. International Journal of Clinical Neuropsychology, 11, 49-54.

Giffard, B., Desgranges, B., Nore-Mary, F., Lalevee, C., Beaunieux, H., de la Sayette, V., . . . Eustache, F. (2002). The dynamic time course of semantic memory impairment in Alzheimer's disease: clues from hyperpriming and hypopriming effects. Brain, 125(Pt 9), 2044-2057. doi: 10.1093/brain/awf209 
Greene, J. D., \& Hodges, J. R. (1996). Identification of famous faces and famous names in early Alzheimer's disease. Relationship to anterograde episodic and general semantic memory. Brain, 119(Pt 1), 111-128. doi: 10.1093/brain/119.1.111

Guillozet, A. L., Weintraub, S., Mash, D. C., \& Mesulam, M. M. (2003). Neurofibrillary tangles, amyloid, and memory in aging and mild cognitive impairment. Archives of Neurology, 60(5), 729-736. doi: 10.1001/archneur.60.5.729

Haslam, C., Kay, J., Hanley, J. R., \& Lyons, F. (2004). Biographical knowledge: modalityspecific or modality-neutral? Cortex, 40(3), 451-466. doi: 10.1016/S00109452(08)70139-4

Hodges, J. R., Erzinclioglu, S., \& Patterson, K. (2006). Evolution of cognitive deficits and conversion to dementia in patients with mild cognitive impairment: a very-long-term follow-up study. Dementia \& Geriatric Cognitive Disorders, 21(5-6), 380-391. doi: $10.1159 / 000092534$

Hodges, J. R., Salmon, D. P., \& Butters, N. (1993). Recognition and naming of famous faces in Alzheimer's disease: a cognitive analysis. Neuropsychologia, 31(8), 775-788. doi: $10.1016 / 0028-3932(93) 90128-\mathrm{M}$

Howard, D., \& Patterson, K. (1992). The Pyramids and Palm Trees Test: a test of semantic access from pictures to words. Bury St Edmonds, UK: Thames Valley Test Compagny.

Joubert, S., Brambati, S. M., Ansado, J., Barbeau, E. J., Felician, O., Didic, M., . . Kergoat, M.J. (2010). The cognitive and neural expression of semantic memory impairment in mild cognitive impairment and early Alzheimer's disease. Neuropsychologia, 48(4), 978-988. doi: 10.1016/j.neuropsychologia.2009.11.019 
Joubert, S., Felician, O., Barbeau, E. J., Didic, M., Poncet, M., \& Ceccaldi, M. (2008). Patterns of semantic memory impairment in Mild Cognitive Impairment. Behavioural Neurology, 19(1-2), 35-40. doi: 10.1155/2008/859657

Kaplan, E., Goodglass, H., \& Weintraub, S. (1983). The Boston Naming Test. Philadelphia: Lea \& Febiger.

Kline, R. B. (1998). Principles and practice of structural equation modeling. New York: Guilford Press.

Laisney, M., Giffard, B., Belliard, S., de la Sayette, V., Desgranges, B., \& Eustache, F. (2011). When the zebra loses its stripes: Semantic priming in early Alzheimer's disease and semantic dementia. Cortex, 47(1), 35-46. doi: 10.1016/j.cortex.2009.11.001

Langlois, R., Joubert, S., Benoit, S., Dostie, V., \& Rouleau, I. (2016). Memory for Public Events in Mild Cognitive Impairment and Alzheimer's Disease: The Importance of Rehearsal. Journal of Alzheimer's disease, 50(4), 1023-1033. doi: 10.3233/jad-150722

Lavallee, M. M., Gandini, D., Rouleau, I., Vallet, G. T., Joannette, M., Kergoat, M. J., . . . Joubert, S. (2016). A Qualitative Impairment in Face Perception in Alzheimer's Disease: Evidence from a Reduced Face Inversion Effect. Journal of Alzheimer's Disease, 51(4), 1225-1236. doi: 10.3233/jad-151027

Leyhe, T., Muller, S., Eschweiler, G. W., \& Saur, R. (2010). Deterioration of the memory for historic events in patients with mild cognitive impairment and early Alzheimer's disease. Neuropsychologia, 48(14), 4093-4101. doi: 10.1016/j.neuropsychologia.2010.10.011

McKhann, G., Knopman, D. S., Chertkow, H., Hyman, B. T., Jack Jr, C. R., Kawas, C. H., . . Phelps, C. H. (2011). The diagnosis of dementia due to Alzheimer's disease: Recommendations from the National Institute on Aging-Alzheimer's Association 
workgroups on diagnostic guidelines for Alzheimer's disease. Alzheimer's \& Dementia, 7(3), 263-269. doi: 10.1016/j.jalz.2011.03.005

McRae, K., de Sa, V. R., \& Seidenberg, M. S. (1997). On the nature and scope of featural representations of word meaning. Journal of experimental psychology. General, 126(2), 99-130. doi: 10.1037/0096-3445.126.2.99

Meeter, M., Eijsackers, E. V., \& Mulder, J. L. (2006). Retrograde amnesia for autobiographical memories and public events in mild and moderate Alzheimer's disease. Journal of Clinical \& Experimental Neuropsychology, 28(6), 914-927. doi:

$10.1080 / 13803390591001043$

Mitchell, T. W., Mufson, E. J., Schneider, J. A., Cochran, E. J., Nissanov, J., Han, L.-Y., . . . Arnold, S. E. (2002). Parahippocampal tau pathology in healthy aging, mild cognitive impairment, and early Alzheimer's disease. Annals of Neurology, 51(2), 182-189. doi: 10.1002/ana.10086

Moscovitch, M., Nadel, L., Winocur, G., Gilboa, A., \& Rosenbaum, R. S. (2006). The cognitive neuroscience of remote episodic, semantic and spatial memory. Current Opinion in Neurobiology, 16(2), 179-190. doi: 10.1016/j.conb.2006.03.013

Moscovitch, M., Rosenbaum, R. S., Gilboa, A., Addis, D. R., Westmacott, R., Grady, C., .. . Nadel, L. (2005). Functional neuroanatomy of remote episodic, semantic and spatial memory: a unified account based on multiple trace theory. Journal of Anatomy, 207(1), 35-66. doi: 10.1111/j.1469-7580.2005.00421.x

Muller, S., Mychajliw, C., Hautzinger, M., Fallgatter, A. J., Saur, R., \& Leyhe, T. (2014). Memory for past public events depends on retrieval frequency but not memory age in 
Alzheimer's disease. Journal of Alzheimer's disease, 38(2), 379-390. doi: 10.3233/jad130923

Nasreddine, Z. S., Phillips, N. A., Bedirian, V., Charbonneau, S., Whitehead, V., Collin, I., ... Chertkow, H. (2005). The Montreal Cognitive Assessment, MoCA: a brief screening tool for mild cognitive impairment. Journal of the American Geriatrics Society, 53(4), 695699. doi: 10.1111/j.1532-5415.2005.53221.x

Reitan, R. M. (1955). The relation of the trail making test to organic brain damage. Journal of Consulting Psychology, 19(5), 393-394. doi: 10.1037/h0044509

Rey, A. (1964). L'examen clinique en psychologie. Paris: Presses Universitaires de France.

Rey, A. (1970). Test de copie et de reproduction de mémoire de figures géométriques complexes. Paris: Éditions du Centre de psychologie appliquée.

Rogers, S. L., \& Friedman, R. B. (2008). The underlying mechanisms of semantic memory loss in Alzheimer's disease and semantic dementia. Neuropsychologia, 46(1), 12-21. doi: 10.1016/j.neuropsychologia.2007.08.010

Rouleau, I., Salmon, D. P., Butters, N., Kennedy, C., \& McGuire, K. (1992). Quantitative and qualitative analyses of clock drawings in Alzheimer's and Huntington's disease. Brain \& Cognition, 18(1), 70-87. doi: 10.1016/0278-2626(92)90112-Y

Seidenberg, M., Guidotti, L., Nielson, K. A., Woodard, J. L., Durgerian, S., Zhang, Q., . . Rao, S. M. (2009). Semantic knowledge for famous names in mild cognitive impairment. Journal of the International Neuropsychological Society, 15(1), 9-18. doi: $10.1017 /$ S1355617708090103

Seni, A., Bédirian, V., Charbonneau, S., Imbeault, H., Limoges, F., \& Rouleau, I. (2010). Utilité clinique de l'analyse des erreurs au test de dénomination de Boston dans le vieillissement 
et la maladie d'Alzheimer. Paper presented at the congrès de la Société québécoise pour la recherche en psychologie (SQRP), Montréal, Canada.

Smith, C. N. (2014). Retrograde memory for public events in mild cognitive impairment and its relationship to anterograde memory and neuroanatomy. Neuropsychology, 28(6), 959972. doi: 10.1037/neu0000117

Squire, L. R., \& Alvarez, P. (1995). Retrograde amnesia and memory consolidation: a neurobiological perspective. Current Opinion in Neurobiology, 5(2), 169-177. doi: $10.1016 / 0959-4388(95) 80023-9$

Thompson, S. A., Graham, K. S., Patterson, K., Sahakian, B. J., \& Hodges, J. R. (2002). Is knowledge of famous people disproportionately impaired in patients with early and questionable Alzheimer's disease? Neuropsychology, 16(3), 344-358. doi: 10.1037/08944105.16.3.344

Tulving, E. (1972). Episodic and semantic memory. In E. Tulving \& W. Donaldson (Eds.), Organization of memory (pp. 381-403). Oxford: Academic Press.

Tyler, L. K., \& Moss, H. E. (2001). Towards a distributed account of conceptual knowledge. Trends in cognitive sciences, 5(6), 244-252. doi: 10.1016/S1364-6613(00)01651-X Van der Linden, M., Coyette, F., Poitrenaud, J., Kalafat, M., Calicis, F., Wyns, C., \& Adam, S. (2004). L'épreuve de rappel libre/rappel indicé à 16 items (RL/RI). In M. Van der Linden (Ed.), L'évaluation des troubles de la mémoire. Présentation de quatre tests de mémoire épisodique avec leur étalonnage (pp. 25-47). Marseille: Solal.

Van Hoesen, G. W., Hyman, B. T., \& Damasio, A. R. (1991). Entorhinal cortex pathology in Alzheimer's disease. Hippocampus, 1(1), 1-8. doi: 10.1002/hipo.450010102 
Vogel, A., Gade, A., Stokholm, J., \& Waldemar, G. (2005). Semantic memory impairment in the earliest phases of Alzheimer's disease. Dementia \& Geriatric Cognitive Disorders, 19(23), 75-81. doi: 10.1159/000082352

Warrington, E. K. (1975). The selective impairment of semantic memory. The Quarterly journal of experimental psychology, 27(4), 635-657. doi: 10.1080/14640747508400525

Wechsler, D. (2000). Échelle d'intelligence de Wechsler pour adultes, troisième édition. Toronto: PsychCorp.

Wechsler, D. (2001). Échelle clinique de mémoire de Weschler MEM-III (WMS-III). Paris: Éditions du Centre de psychologie appliquée.

Wiese, H. (2011). The structure of semantic person memory: evidence from semantic priming in person recognition. British Journal of Psychology, 102(4), 899-914. doi: 10.1111/j.2044-8295.2011.02042.x

Wilson, R. S., Leurgans, S. E., Boyle, P. A., \& Bennett, D. A. (2011). Cognitive decline in prodromal Alzheimer disease and mild cognitive impairment. Archives of Neurology, 68(3), 351-356. doi: 10.1001/archneurol.2011.31 